\title{
Mobilidade Humana em Contexto de Mudanças
}

Mariângela Moreira NAScIMENTO, Universidade Federal da Bahia

O artigo discute os aspectos e impactos das mudanças do capitalismo e do crescente fluxo migratório no século XXI. Analisa a nova configuração do poder capitalista e a nova ordenação produtiva, onde a mobilidade humana se torna uma condição necessária.

PALAVRAS-Chave: Mobilidade Humana. Poder. Trabalho. 


\section{Apresentação}

Esse artigo traz algumas reflexões acerca das atuais transformações do capitalismo e os impactos da explosão demográfica associada ao fluxo migratório, que tem se tornado a fonte de resistência aos mecanismos de restrições da política de migração dos últimos anos. Discute a nova configuração do poder capitalista, que vem redesenhando o território global e estabelecido uma nova ordenação produtiva, onde a mobilidade do trabalho torna-se, cada vez mais, uma condição necessária, ao mesmo tempo em que o mundo capitalista vem impondo fortes restrições que limitam e controlam a circulação de pessoas.

É fato que as relações de poder global mudaram, e nessa nova engenharia política o poder do capital tem se coloca acima de todas as nações, organizado numa estrutura unitária e regulatória.Para a execução dessa política, uma nova noção de direito passa a fundamentar e justificar essa ordenação na sua capacidade de fazer uso da força, e passa a manter sobre o seu total controle os resultados políticos de qualquer acontecimento no âmbito global. É o caso das intervenções dos países capitalistas dominantes em territórios alheios, que encontram sua base no direito de polícia e na capacidade de usar a força policial. Nesse caso, a violência se revelou um dispositivo de controle que mantêm a vida individual e da espécie sob a vigilância total do poder. Portanto, a novidade dessa nova ordem está, esclarece Agamben (2007), em anular radicalmente todo o estatuto jurídico do indivíduo, produzindo, dessa forma, um ser juridicamente inominável e inclassificável. A estrutura constitutiva da autoridade se vale, para isso, dessas duas fontes de sustentação tornadas legítimas, o poder jurídico de reinar sobre a exceção e a capacidade de usar a força policial. Nesse caso, torna-se uma ficção o próprio Estado de direito.

O Estado capitalista, além de ser responsável pelo fluxo do capital e mercadorias, passa a ter um papel fundamental na regulamentação e deslocamento de populações, fazendo valer os instrumentos de repressão e restrição. Nesse caso, a possibilidade de distinguir entre a vida e o direito passa a coincidir com a articulação da máquina do poder, de um poder de controle e a potencialidade de produção do capital. A vida, do mesmo modo que o direito, passa a ser um produto da máquina biopolítica. Está em prática o grande alcance da máquina biopolítica por meio de redes flexíveis e flutuantes, estendendo à todas as dimensões, dentro e fora dos locais estruturados pelas 
instituições, ou seja, esse poder se estende às nossas práticas diárias e cotidianas.

Podemos assim identificar a realidade das redes de comunicação e informação como sendo uma relação orgânica com o desenvolvimento da nova ordem global e de toda a vida social. Essa é uma das bases da nova estrutura do poder global, que passa a não identificar nada do que possa estar fora do seu alcance, tornando os seus mecanismos de controle imanentes à vida social. Esses mecanismos estão inseridos nos comportamentos e hábitos de todos $\backslash$ as nós, de toda a população produtiva. Por isso, o poder só pode adquirir comando sobre toda a população quando a vida se torna função integral do poder, ou seja, quando a vida se torna objeto constitutivo de poder. Sendo assim, todo o corpo social integra-se à máquina biopolítica, e não tem como escapar dessa estrutura de poder. Isso vai exigir, por parte da estrutura do poder global, uma adequada tecnologia para a ordenação e sistematização da vida social, valendo-se não apenas do aparato tecnológico da comunicação e informação, mas da nova natureza do trabalho e do seu desenvolvimento real da produção. É a máquina da tecnologia da informação e comunicação que passa agora a organizar o movimento da vida social, expandindo e multiplicando as conexões em redes. $\mathrm{O}$ poder globalizado estrutura-se para dominar o sistema de produção e intervir nas situações que coloca em risco esse sistema. As suas relações de poder nada mais são do que expressões da nova força produtiva biopolítica e institucional que, cada vez mais, se estende à sociedade mundial.

Hoje, quase toda a população mundial é, em certa medida, absorvida pelas redes de exploração capitalista e a elas está subordinada. A exploração e a dominação, na fase atual do capitalismo, têm se revelado mais intensas e brutais do que no passado; a concentração da riqueza mundial nas mãos de poucos acontece de modo muito mais nítido e violento. $\mathrm{O}$ que faz crescer a população pobre e a mobilidade humana em todo canto do planeta, confirmando o fato de que as linhas geográficas e raciais de opressão, exploração e patriarcado estabelecidas durante a era do colonialismo e do imperialismo, em muitos sentidos não declinaram; pelo contrário, aumentaram substancialmente, expressando um domínio sem fronteiras. (NEGRI; HARDT, 2006) A sociedade está totalmente absorvida pelo poder do Estado globalizado. Ela foi absorvida totalmente pelas redes de controle que mantém a população em uma ordenação produtiva, que já não conta mais com as velhas fronteiras, a fabril, a nacional, por exemplo. 
Mas ao mesmo tempo em que esse comando envolve todos os elementos da vida social, depara-se, no entanto, com uma extensa pluralidade coordenada e mediada pela sociedade, revelando um novo lugar para as resistências, que, independente de serem tidas como marginais e excluídas, se tornam ativas no centro de uma sociedade que se abre em redes, redes de cooperação. (NEGRI; HARDT, 2006) Essa situação desencadeia uma reação sem fronteira, para além das divisões nacional, colonial e imperial, das massas revoltadas e excluídas, da população migrante, movida por seu desejo de libertação, exercendo o seu direito de fuga.(MEZZADRA, 2012) Trata-se de movimentos espontâneos dos \as trabalhadores $\backslash$ as sem nenhuma organização externa, que surge diretamente das próprias condições materiais de luta encontradas pelos $\backslash$ as trabalhadores $\backslash$ as de todo mundo, impulsionadas pelo desejo de libertação que transforma a subjetividade no fundamento da organização transformadora, produzida no próprio processo de trabalho e relacional. Essa reação colocou uma multidão em movimento planetário, o qual passa a ser o locus da resistência da nova ordenação do poder global, colocando em evidência a crise das instituições liberais que sustentaram por tantos anos a ideia de democracia e direitos. A internacionalização das lutas, portanto, ganha outra definição nessa nova abordagem analítica. A questão espacial, territorial, é redefinida a partir da compreensão do local e global como os dois lados da mesma moeda, em que o movimento local de reação incide sobre o movimento global da dominação capitalista.

Esse artigo traz esse tema com a intenção de proporcionar um novo olhar sobre o fenômeno migratório, visto em um contexto de mudanças, onde o principal protagonista é o indivíduo em fuga buscando a sua libertação, seja das condições precárias de vida, de trabalho, de danos ambiental, da opressão cultural, patriarcal e social.

\section{Nova Composição do Mundo do Trabalho}

Uma análise acerca do fenômeno da migração no século XXI, que tem se constituído em um forte movimento de reação às políticas de restrição e controle, tem que levar em conta o contexto das novas relações do poder global, das transformações no mundo do trabalho e dos fluxos de gerações de diferenças e identidades como base teórica e empírica. Só assim é possível fundamentar o poder de fazer história dos movimentos migratórios, procurando identificar tanto a base ontológica 
alternativa que reside nas práticas criadora e produtiva de novos $\backslash$ as atores $\backslash$ ras que resistem, como identificar a condução dos processos da produção de subjetividade para a constituição de uma alternativa social e política; ou seja, identificar o momento em que a produção das subjetividades é também a construção, pelos novos \as atores \ras, de um novo poder constituinte, de resistência, construído numa condição livre das estruturas estabelecidas pelas fronteiras da territorialização e da luta contra as políticas de restrição, controle e suas estruturas de aprisionamento.

A intenção aqui não é apontar uma nova racionalidade como alternativa às análises que as ciências humanas tem sobre o tema, tratase de buscar uma nova estratégia teórica-metodológica para apreender e compreender, a partir dessas mudanças globais, a realidade migratória como um fenômeno de resistência e transformação do capitalismo. $\mathrm{Ou}$ seja, trata-se de adotar uma metodologia que possa reconhecer a produção de novas subjetividades como possibilidades libertadoras, criadas com a globalização dos $\backslash$ as trabalhadores $\backslash$ as, da migração internacional, e capaz de perceber a constituição da potência transformadora dos novos protagonistas políticos.

Hoje, fazer uma análise do novo contexto global, exige compreender a extensão que ganhou o movimento migratório, que não é mensurado apenas pela quantidade do seu alcance, mas pela capacidade de deslocamento, pela fluidez do capital que passa a estar em todos os mercados globais e pela intensificação das políticas de restrição que tem intensificado a precarização do trabalho e suspenso o acesso aos direitos à população migrante.

As relações produtivas da atual fase capitalista foram alteradas, hoje o processo produtivo envolve uma massa de trabalhadores $\backslash$ ras em circulação e inseridos $\backslash$ as em redes de cooperação. Sua realização revela um novo campo de valorização que passa a eleger desde o elemento técnico ao afetivo no processo produtivo. O trabalho na sua nova fase é intelectual, comunicativo, técnico-científico, afetivo, que envolve a interação e a cooperação social. O trabalho, nesse caso, envolve não apenas a totalidade das atividades econômicas, ele não se limita a sua materialidade como na fase industrial do capitalismo, nessa nova fase ele torna-se imaterial, ou seja, são os processos relacionais do trabalho que determinam e definem as suas dimensões objetivas. A mudança de paradigma ocorre não na competição feroz, mas em um compartilhamento, não na sustentação de antinomias próprias da era 
industrial, como exemplo o trabalho e não-trabalho, trabalho produtivo e improdutivo. Hoje toda atividade insere-se no processo produtivo, criando muito mais do que bens materiais, mas ativos imateriais incomensuráveis. Esse contexto de mudança se define com o conceito de sociedade pós-industrial ou fase pós-fordista, que diz respeito as transformações no capitalismo e se distingue pelo fortalecimento do capital frente ao Estado, na concorrência econômica global acompanhada pela descentralização das empresas, com o objetivo de globalizar sua produção para aumentar seus ganhos; e isso foi possível com a erosão do Estado-Nação e o seu (re)direcionamento para desfazer o contrato do bem-estar social (SANSON, 2009)

Nessa transição para a economia informacional,

a linha de montagem foi substituída pela rede como método de organização da produção alterando as formas de cooperação e comunicação dentro de cada lugar que produz e entre os lugares de produção. (...) De fato, a rede de cooperação no trabalho não requer território nem centro físico (NEGRI/HARDT, 2006, p. 316-317).

É importante lembrar que a cooperação não é imposta e organizada de fora como foi nas épocas passadas do capitalismo, na sua fase industrial, mas uma cooperação que é imanente à própria atividade laboral e que desenvolve, ao mesmo tempo, o potencial e o antagonismo do trabalho vivo em um nível nunca antes experimentado, e que vai se configurar nas novas formas de resistência. (NEGRI/HARDT,2006)

Hoje nos deparamos com um novo antagonismo que sinaliza as transformações das relações de poder e o surgimento de novas subjetividades que indicam os novos atores no qual habitam o espaço da liberdade, não mais como foi definido pela modernidade, mas um novo campo de constituição da democracia radical resultante de inúmeras redes de trabalho social, de cooperação e de resistência. Quando olhamos para "a nova qualidade dos processos de trabalho imaterial e da cooperação social nas suas diferentes formas, começamos a reconhecer os circuitos alternativos da valorização social e as novas subjetividades que emergem desses processos" (NEGRI \HARDT, 2004, p. 27).

O trabalho, nessa nova composição, não pode ser visto apenas como uma atividade qualquer, produtora de bens, de objetos a serem consumidos, mas como atividade específica, socialmente reconhecida como produtora de valores, uma força ativa de negociação, que está 
presente em todas as mercadorias e é substância comum de todas as atividades de produção.

A relação trabalho e valor, portanto, não pode ser tratada apenas como fator constitutivo da sociedade capitalista, mas, também, como resistência ao capitalismo e afirmação de que outra sociedade é possível. Mesmo na obra de Marx, lembra Negri, a teoria do valor é também apresentada de outra maneira que não a do "processo capitalista de valorização"; Marx, a despeito da sua teoria de valor-trabalho, também considera o valor como uma figura antagonística, como sujeito dinâmico de ruptura do sistema. A força-trabalho social é considerada, assim, um elemento valorizante da produção, que produz subjetividades e reproduz a sociedade, ampliando a sua capacidade de resistir e transformar. Tratase de um mais-valor que é gerado pela cooperação e relações sociais que considera o tempo de não-trabalho, o tempo de aprendizagem, o tempo dos afetos, o tempo do consumo cultural, o tempo de vida. Esta cooperação e relação social extratrabalho não é paga pelo salário, obviamente, mas constitui uma força produtiva fundamental. (SANSON, 2009). E isso acontece independente do funcionamento da clássica lei capitalista do valor, da medida do valor-trabalho, ou seja, daquele valor determinado pela relação da mercadoria e o tempo-trabalho socialmente necessário a sua produção, definido por Marx (NEGRI \HARDT, 2004).

Estamos falando do trabalho imaterial, que é criador de valores que afirmam a coletividade, capaz de impulsionar um movimento de resistência, de provocar novos processos de luta e de criar novas expressões da potência constituinte. Nessa nova configuração do trabalho, na qual a indústria deu lugar aos serviços, à informatização e à comunicação, que colocaram homens e mulheres em um emaranhado de redes e promoveu uma extensa cooperação social por toda a sociedade, se tornou, de fato, o centro de toda a ação humana, está presente em todas as suas dimensões, desde a intelectual à fabricação, a afetiva à comunicação, a subjetiva à objetiva.

Diante das mudanças das relações do trabalho, o mundo pósindustrial não mais reconhece o sujeito "operário massa", o operário fabril - o tradicional agente das transformações capitalistas do século passado que esteve presente nas lutas emancipatórias; esse deu lugar a um novo protagonista do mundo globalizado, envolto num mundo informatizado, que não mais se prende ao trabalho regulamentado da fábrica, mas agora é à imaterialidade do trabalho que se coloca como 
espaço para a recomposição política do antagonismo, como contínuo motor da história.

Entretanto, isso não quer dizer que a nova composição do trabalho esteja menos sujeita às formas de exploração e opressão, pelo contrário, as condições postas pelas novas relações produtivas tendem a estender com maior intensidade a precariedade e vulnerabilidade no mundo do trabalho.

Essas mudanças fazem parte das transformações estruturais do capitalismo, que, em virtude da ampliação da sua capacidade de domínio e exploração, da subsunção da sociedade pelo capital, exigem novos pilares teóricos e conceituais diferentes daqueles que sustentaram muitas correntes analíticas da era moderna.

As interpretações são muitas, cada uma a seu modo apontam os efeitos da transformação que o capitalismo tem passado nas últimas décadas, seja na direção da supremacia da cultura sobre a economia, do sepultamento da metalinguagem, da acumulação flexível, todos evidenciam de certa forma o enfraquecimento da base valorativa e normativa que deu origem ao projeto da modernidade.

É preciso entender, a partir daí, as novas relações de poder que foram estabelecidas e o novo formato das lutas dos $\backslash$ as trabalhadores $\backslash$ as diante dessas transformações estruturantes das relações produtivas, principalmente diante do crescente movimento migratório, bem como identificar os dispositivos de controle que ampliaram a capacidade de domínio do poder do Estado na nova realidade global e a emersão dos novos formatos de reação e luta que passam a inserir em sua dinâmica outras subjetividades e novos atores políticos.

\section{Os Novos Protagonistas em Meio às Mudanças}

O capitalismo, como um sistema de dominação, promove e reproduz a discriminação de gênero, raça, etnia, sexualidade, mobilidade humana, classe social, para estabelecer suas hierarquias de controle e restrição. Muitas análises sustentam a ideia de que o atual desenvolvimento do capitalismo tem como ponto de explicação, primeiro, a nova realidade tecnocrática, e, segundo - decorrente do primeiro ponto -, a perda do papel central das classes sociais no processo de luta contra o capital. Daí a tendência dessas análises de identificarem as relações sociais como um somatório de múltiplos casos setoriais, 
envolto às suas temáticas pontuais, capazes de ocupar o lugar vazio da classe trabalhadora como foi no passado. Com as transformações do processo produtivo capitalista, impulsionadas pelas novas tecnologias de informação e comunicação, novos atores emergiram no cenário das lutas sociais. Ou seja, grupos organizados em torno de temas específicos e que não necessariamente tinham vínculos entre si, ocuparam o cenário das lutas sociais e de resistência ao capital, distanciando-se, assim, do formato classista da ortodoxia marxista. Tais grupos não traziam uma proposta de transformação do capitalismo, mas colocaram em xeque muitos valores e instituições que sustentam as relações capitalistas, e, na medida em que suas lutas ganharam dimensão global, formaram um ciclo de lutas que revelou o esgotamento da herança moderna.

Hoje, a hierarquia disciplinar da ordem fabril, não se limita a articular apenas as funções de comando capitalista, agora ela se articula também dentro das relações sociais de gênero, raça, etnia, sexualidade, por exemplo. Os grupos identitários emergiram como práticas sociais da crítica da ordem material do trabalho e de suas bases disciplinares, contribuindo assim para o desmoronamento dos mecanismos de regulação keynesianos e das hierarquias disciplinares, fordista e taylorista. É o momento em que a entrada de novos atores nas lutas, transforma a sociedade num campo fértil para criar e conquistar novos direitos e apontar alternativas de lutas.

O novo contexto laboral trouxe, desse modo, novas formas de relações sociais, que vão além daquela esboçada pelas tradicionais configurações do capital. Os avanços tecnológicos ao contribuir com a reconfiguração do trabalho, trouxe a diluição da fronteira entre a fábrica, o escritório e a casa. Isso foi um facilitador da inserção crescente da mão de obra feminina, da população flutuante e dos serviços no centro do processo produtivo; bem como o fim da separação secular entre trabalho manual e intelectual, produtivo e improdutivo, e a incorporação de várias modalidades no processo produtivo.

A nova composição da força de trabalho e suas relações com o capital significou uma maior reação do \a trabalhador \ra à sujeição ao capitalismo, ou seja, novas formas de resistências passam a ser praticadas. Sendo assim, podemos afirmar que o fim do modo de regulação que predominou no século XX significou o fracasso do capital em impor uma determinada forma de organização do trabalho diante da resistência do movimento dos novos atores. Neste período de reestruturação capitalista, crescem as tensões sociopolíticas e o nível de 
contradições, trazendo para o cenário das lutas esse novo protagonista, um $\backslash$ a trabalhador $\backslash$ a sem fronteiras, um trabalhador $\backslash$ a que luta pelo direito a ter direitos, um trabalhador $\backslash \mathrm{a}$ que se revela pelas suas diferenças.

Nessa era pós-industrial, a figura do trabalhador $\backslash$ a surge com características subjetivas de difícil sujeição ao capital, e a nova leitura da dinâmica do capitalismo coloca de lado as ideias das leis inexoráveis da economia como vetor das contradições entre capital e trabalho. $\mathrm{O}$ que significa a recusa da análise economicista e a eleição dos elementos subjetivos das relações sociais como indicadores da nova natureza das lutas sociais.

Os novos enfrentamentos promovem mudanças na composição política e na dinâmica das lutas dos \as trabalhadores \as. São essas modificações da força de trabalho no processo de reprodução social que o antagonismo político se manifesta e atribui ao trabalho industrial papel secundário na organização capitalista, apontando para um novo campo onde as lutas se manifestam, revelando os novos protagonistas.

São esses momentos de composição, recomposição e decomposição que caracterizam os ciclos de luta e a emersão do sujeito antagônico. Ciclos de lutas que, como dito antes, em decorrência dos avanços da tecnologia da informação se estendem a todos os campos de ação da sociedade, envolvendo seus vários segmentos. O que implica dizer que todos os movimentos da sociedade estão inseridos no processo produtivo. A fábrica não mais se restringe a um espaço físico em que se concentra a produção fabril. As operações laborais se estendem a toda a sociedade; se descentralizam e se difundem aos múltiplos campos sociais. A sociedade passa a ser um celeiro de todo tipo de serviços, adaptando-se às transformações do capital e, ao mesmo tempo, revelando-se potente diante dele.

Portanto, o avanço tecnológico não tem promovido apenas a subjugação do $\backslash a$ trabalhador $\backslash a$, mas, na medida em que essa tecnologia se torna global, o capital é impelido a difundir esse conhecimento a todo o processo produtivo, promovendo uma crescente sociabilidade do trabalho através de formação de redes de cooperação, criando possíveis barreiras à cooptação do capital. Nesse contexto, a comunicação representa hoje para o mundo do trabalho o que a relação salarial foi para o operário industrial, ou seja, os recursos de informação fazem parte do conjunto de bens e serviços que o capital deve oferecer aos $\backslash$ as 
trabalhadores \as para o seu desenvolvimento (ALTAMIRA, 2009). Passando a incluir, na composição e na ideia de classe, todo tipo de trabalhador $\backslash \mathrm{a}$, desde donas de casa a cientistas, dos empregados aos desempregados, imigrantes aos trabalhadores autóctones. Ou seja, a todas as categorias sociais encarregadas de reproduzir o capital e resistir a ele.

Essa é a base paradigmática das análises que procuram identificar e compreender os atuais movimentos de libertação dos trabalhadores e trabalhadoras, e as novas formas de resistências às políticas de controle, exploração e exclusão.

\section{A Mobilidade Humana e o Processo Produtivo}

A atual explosão demográfica associada ao fluxo migratório crescente, a pauperização da maior parte da população mundial, a precarização do trabalho, tornaram ineficazes os dispositivos para controlar e conter os movimentos dessa multidão fluida, uma multidão que tem se apresentado cada vez mais irredutível aos mecanismos de aprisionamento do poder global.

O poder se instrumentaliza com novas estratégias e mecanismos de contenção do fluxo migratório. Para isso, o Estado, além do uso do aparato jurídico e policial, lança mão da "circulação do medo", promovendo uma guerra global, em nome do combate ao terrorista, potencial ou real, e desencadeia um poder de polícia em escala global, fazendo circular por todos os cantos do mundo o medo como sentimento de contenção das pessoas.

Essa tem sido a forma encontrada pelo poder do Estado de promover a instabilidade e insegurança no meio da população para tornar ainda mais vulnerável o crescente deslocamento de trabalhadores $\backslash$ as pelo planeta. Essa vulnerabilidade permite ao poder manter a população numa rede de circulação, reativando e garantindo a sua capacidade de controle, respondendo, dessa forma, os desafios postos pela crescente expansão e mobilização da população pobre no mundo.

O sentimento do medo foi desencadeado pela afirmação da guerra global permanente, ou seja, de um poder de polícia em nível global, para conter a potência dos novos protagonistas que emergem das novas relações produtivas. $\mathrm{O}$ que torna diferente essa nova modalidade 
de controle é, como nos referimos acima, a utilização dos vários recursos tecnológicos da informação e comunicação, que possibilita, em tempo veloz, disseminar o medo em todas as partes do mundo. Daí a rede de comunicação ter se tornado o alvo de fortes competições e fusões das corporações transnacionais. A síntese política do novo espaço social (des)territorializado,

é fixada no espaço de comunicação.É por isso que as indústrias de comunicação assumiram posição central. Elas não apenas organizam a produção numa nova escala e impõem uma nova estrutura adequada ao espaço global, mas também tornam imanente sua justificação. $\mathrm{O}$ poder, enquanto produz, organiza; enquanto organiza, fala e se expressa como autoridade. A linguagem, à medida que comunica, produz mercadorias, mas, além disso, cria subjetividades, põe umas em relação às outras, e ordena-as. As indústrias de comunicações integram o imaginário e o simbólico dentro do tecido biopolítico, não simplesmente colocando-os a serviço do poder mas integrando-os, de fato, em seu próprio funcionamento (NEGRI/HARDT, 2006, p. 52).

Além dessas estratégias para disseminar o medo, o capitalismo, ao se organizar a partir de redes de circulação, redesenha o território global e estabelece novos espaços do ciclo de produção do capital, do mesmo modo, promove uma mobilidade do trabalho nunca antes vista e estabelece "contenções mediante redes de condicionamento, e não mais de organização" (COCCO, 2004, p. 9). Redes que não tem um centro e nem são hierarquizadas, são verdadeiras teias espalhadas pelo mundo, interconectadas por extensas rotas, promovendo e intensificando o processo de desterritorialização. São também redes que sofrem fortes pressões e disputas entre as corporações para mantê-las sobre o seu controle.

A nova dinâmica da produção, que agora incorporou na sua estrutura a interação e a difusão das redes, promove e controla a circulação e mobilidade de pessoas, e redefine, por sua vez, novas composições geopolíticas e expressam a nova natureza da resistência, que passa a ter papel constitutivo, estabelecendo a dimensão constituinte do processo de luta dos $\backslash$ as trabalhadores $\backslash$ as. As formas de resistência, do contrapoder, foram, nesse contexto histórico, se modificando, e foi isso que impôs ao capital a necessidade de buscar novos mecanismos de controle e de contenção da mobilidade humana.

Um dos fatores que melhor explica as mudanças no processo produtivo e de configuração do poder global, é a emersão da potência 
dessa grande multidão flutuante, que reagiu aos impedimentos e controles que lhes foram impostos ao longo do século XX e continua no século XXI. A partir dessa reação, novas formas de resistir apareceram e novas subjetividades surgiram no cenário das lutas sociais que redefinem o papel dos novos atores. E isso afronta a capacidade do sistema capitalista de manter sobre controle essa multidão fruída, mutante e imprevisível. Essa reação ocorre através da disseminação e contaminação de novos valores e comportamentos no âmbito global, e das redes consolidadas que resistem ao controle, graças a sua estrutura interativa e descentralizada de cooperação.

\section{Novas Formas de Resistência}

Nesse contexto de transformações globais é importante analisar os processos migratórios não apenas como fluxos de trabalhadores $\backslash$ as, mas como movimentos sociais que resistem, o que vai permitir olhar o $\backslash \mathrm{a}$ migrante como um ser singular e individualizado, identificando-o $\backslash$ a como protagonista político capaz de resignificar os processos de produção e reprodução do capital e do modo de vida. Dessa forma, o \a migrante passa a ser reconhecido como promotor das novas lutas e resistências, isso faz com que seja desconstruído a imagem de sujeito passivo, subalterno e carente de cuidados. Nessa perspectiva, em que a subjetividade ganha lugar central nas análises e nas lutas, nos possibilita identificar as reais possibilidades e limites das pessoas em situação de mobilização, e tornar mais perceptível as contradições geradas pelas tensões entre o desejo de liberdade e mobilidade das pessoas e as políticas de controle e restrições por parte dos Estados, bem como as tensões geradas, de um lado, pelas políticas de restrições da mobilidade humana, do outro, pela expansão da livre circulação do capital e de mercadorias.

O movimento migratório tem se confrontado com essas medidas de restrições que são centrais para o funcionamento exitoso das novas relações produtivas e reprodutivas do capital. Entretanto, para Mezzadra, tais medidas trazem grandes desafios a produção capitalista em escala global ao se defrontarem com a turbulência e conflitos advindos do crescente fluxo migratório (MEZZADRA,2012). A migração ao causar turbulência ao mundo capitalista, coloca em xeque as instituições liberais, a democracia, a cidadania, os direitos humanos, e tem evidenciado o impasse que a economia financeira se encontra com 
suas medidas perversas de superação, através de superexploração e precarização do trabalho.

$\mathrm{O} \backslash \mathrm{a}$ imigrante ao chegar no lugar de destino como força de trabalho se torna um problema a ser enfrentado pelo Estado, já que a necessidade do mercado de trabalho é circunstancial, e o imigrante é tratado como um ser provisório e descartável, mesmo que esta provisoriedade dure mais do que o previsto e desejado. Ele ou ela não deixará nunca de ser um $\backslash$ a estrangeiro $\backslash$ a nas terras dos autóctones, e em muitos casos isso se aplica ao retornarem ao lugar de origem. A ideia do retorno, segundo Sayad (2000), acompanha, na maioria dos casos, a população migratória que mantém laços duráveis com a família e a comunidade de origem. Entretanto, ao retornar o $\backslash$ a migrante leva o estigma de não pertencer a lugar nenhum, mesmo na sua terra de origem. Um dos impactos da crescente movimentação migratória é a desconfiguração do sentido de "pertença", de não pertencer a lugar nenhum, o que tem provocado repercussão sobre a configuração objetiva da cidadania, atuando, desse modo, para o enfraquecimento da sua circunscrição nacional (MEZZADRA, 2012). Podemos assim afirmar que os movimentos migratórios ao se expandirem em um contexto de mudanças do capitalismo, decorrente das transformações do processo produtivo e do recrudescimento da perda de direitos, acabam por afetar determinado modelo de cidadania, aquele fundamentado na cultura nacional, que elegeu o indivíduo enquanto cidadão portador de direitos, imagem que expressa a racionalidade do Estado moderno. Os $\backslash$ as migrantes tornam-se aqueles $\backslash$ as que melhor expressam as contradições e o enfraquecimento dos valores que legitimaram historicamente a relação Estado e sociedade. Essa condição é possível na medida em que os $\backslash$ as migrantes se revelam sujeitos ativos capazes de ultrapassar as restrições imposta pelas políticas de controle da mobilidade humana.

As migrações como fenômenos constitutivos da dinâmica do desenvolvimento capitalista, transfere aos Estados a criação e execução das políticas de controle e restrição. É através dos enfrentamentos do modo de produção capitalista diante do fluxo migratório que são definidas as políticas disciplinares e regulatórias dos $\backslash$ as trabalhadores $\backslash$ as inseridos $\backslash$ as no mundo do trabalho. A relação de tensões e conflitos entre o desejo de libertação e a prática opressora é o elemento estruturante do modo de produção capitalista. Vistas nessa perspectiva, as migrações são referências paradigmáticas na construção dessas políticas, que reestruturam e movimentam as relações no 
trabalho. O resultado imediato dessas tensões e conflitos é o fortalecimento das fronteiras e a expansão da política de restrição e, apesar da manifestação de muitos governos em querer expulsar os imigrantes, tais medidas não tem sido capazes de conter a crescente onda de mobilidade humana no âmbito global, colocando homens e mulheres em confronto com as novas transformações no mundo do trabalho baseado em princípios de flexibilidade e precarização.

Nesse contexto, a questão a ser enfrentada é a relação entre cidadania, Estado e migração, principalmente quando se pensa a cidadania para além do status jurídico-legal circunscrita na nacionalidade. A dimensão teórica e prática da cidadania é uma ferramenta analítica que nos ajuda a mensurar a crise institucional e avaliar as condições da vida, e isso nos permite analisar, com mais critérios teóricos e empíricos, a relação entre o universalismo dos direitos, como os chamados direitos humanos, e o particularismo de pertença, que é identificado pela inserção nacional da cidadania. (MEZZADRA,2012) Essas questões trazem desafios a tradicional configuração da cidadania quando confrontada com a realidade global, que dá sinais evidentes do enfraquecimento do vínculo "naturalizado" dessa relação codificada na cultura nacional, que sempre manteve e reproduziu a linha divisória entre a inclusão e a exclusão, o legal e ilegal. A definição dos códigos de inclusão \legalidade nos espaços da cidadania e os mecanismos de regulação da inclusão e exclusão são desafios que o Estado tem sido chamado a repensar diante da realidade da migração. Pensar a migração, diz Sayad, "significa pensar o Estado, e é o Estado que se pensa a si próprio quando pensa a migração" (SAYAD, 2000) E pensando a si mesmo, o Estado promove a inclusão do migrante enquanto excluído, enquanto força de trabalho vulnerável às condições de precariedade e degradantes. Mesmo aqueles $\backslash$ as que conseguem benefícios assistenciais do Estado, estão privados de direitos, e isso coloca em questão a base do Estado de direito e das relações democráticas. Essa realidade problematiza e exige um modelo não nacional de direitos, que garanta e redefina a universalidade dos direitos humanos. $\quad \mathrm{O}$ acesso dos $\backslash$ as migrantes a alguns direitos específicos definidos pela condição cidadã, não se traduz, na verdade, em obtenção de status de cidadania. Dessa forma, a inclusão do $\backslash$ a migrante trata-se de um "dispositivo de sujeição que conduz à reprodução de uma multiplicidade de regimes de trabalho caracterizados por vários graus de coerção”.(MEZZADRA, 2012,p.14) O enfraquecimento da relação entre 
direitos de cidadania e o seu estatuto jurídico-legal é também enunciado pela falência do Estado social e pelas transformações do modo de produção capitalista, mencionadas acima. Mudanças que não apenas realçam a socialização conflitiva dos $\backslash$ as trabalhadores $\backslash$ as migrantes, mas tornam a posição laboral um critério exclusivo de acesso a cidadania, mesmo que seja uma cidadania restritiva e não passe de um dispositivo de sujeição.

A inserção da força de trabalho migrante no mercado de trabalho é a sua única garantia de acesso a alguns direitos, dentro das condições previstas de migração requeridas pelo país de destino. $\mathrm{Na}$ verdade, estamos tratando aqui de mais uma contradição do quadro migratório: se de um lado há as restrições de mobilidade da migração constituída de força de trabalho, do outro temos a inscrição dessa força de trabalho no processo produtivo como condição única ao acesso a alguns direitos. Nesse caso, a codificação da pertença com base nacional passa a operar circunstancialmente e oportunamente, atendendo as exigências laborais locais.

Os recentes estudos que tem identificado essas contradições e paradoxos da relação Estado, trabalho e migração, vêm se deparado com as dificuldades de classificar as chamadas causas "objetivas" do fenômeno migratório; afinal, como apontar as causas "objetivas" diante de um fenômeno carregado de elementos de imprevisibilidade e que se expressam através da multiplicação e aceleração das interconexões que caracterizam o mundo da globalização? Ou seja, como analisar o fenômeno migratório sem necessariamente centralizar a questão econômica, e eleger como referência analítica os fatores subjetivos? Questões que se estendem principalmente a migração feminina. Por exemplo: como identificar a subalternidade da mulher migrante e associar a sua mobilidade a fatores que não seja a família, mas que possa ser interpretada como libertação de uma condição opressora e machista.

Nesses termos, a migração não representa simplesmente uma resposta forçada pela necessidade, é possível pensar o $\backslash$ a migrante a partir de sua decisão consciente de buscar uma nova experiência de vida, imprimindo assim, na sua mobilidade, um processo autônomo, afirmando as suas determinações subjetivas que estão na origem de suas decisões. 


\section{Considerações Finais}

A mobilidade humana é um tema, cada vez mais, presente nos debates acadêmicos e nas análises das ciências humanas e os estudiosos têm procurado novas estratégias teóricas-metodológicas para compreender e analisar os impactos que o crescente fluxo migratório tem causado ao capitalismo globalizado, assim como tem procurado identificar as novas formas de resistência e enfrentamento desse movimento em relação as políticas de controle e restrições.

A migração sempre fez parte da história humana e acontece em todos os cantos do mundo. Os motivos que levam os/as migrantes a saírem do país de origem não se explicam e se resumem apenas pelas péssimas condições de vida, guerra, catástrofes ambientais, trabalho etc. O processo migratório é também um momento de resistência e produção através da luta, da criação de estratégias de vida. Essas formas de resistência promovem a subversão de barreiras e exigem mudanças; ou seja, a presença do $\backslash$ a migrante cria e transforma, nos lugares aonde chega, novas formas de relação, modos de estar e ser no mundo, em um processo constante de produção de novos laços intersubjetivos. Os $\backslash$ As migrantes revelam-se extremamente potentes através de seus movimentos, em suas lutas diárias por direitos e cidadania. Esse movimento pelo reconhecimento enquanto ser de direitos, tem colocado em evidência a precarização e superexploração do trabalho e o enfraquecimento da democracia, que se revela incapaz e desestrumentalizada institucionalmente para lidar, de modo humanitário, com a população migratória. Nesses termos, a condição do \da migrante desencadeia uma grande tensão subjetiva ao resistir as barreiras do poder, o que tem provocado as reconfigurações do poder global e das novas relações produtivas e reprodutivas do capital.

\section{Referências Bibliográficas}

AGAMBEN, Giorgio. Estado de Exceção. São Paulo: Boitempo, 2007. . Homo Sacer - o poder soberano e a vida nua I. Belo Horizonte: Editora UFMG,2007.

ALTAMIRA, César. Os Marxismos do Novo Século. Rio de Janeiro. Civilização Brasileira,2009. 
ARENDT,Hannah. A Condição Humana. Rio de Janeiro: ForenseUniversitária.1987.

COCCO, Giuseppe; GALVÃO, Alexander Patez; SILVA, Gerardo; (Orgs). Capitalismo cognitivo. Rio de Janeiro: DP\&A editora, 2003.

COCCO, G. Democracia e Socialismo na era da subsunção real: a construção do comum. In O Mundo Real - socialismo na era pósneoliberal.Porto Alegre: L\&PM, 2008.

. Trabalho e Cidadania. Produção e direitos na era da globalização.São Paulo:Cortez Editora, 2004.

- A riqueza dos pobres contra a pobreza dos ricos, Jornal Lê Monde Diplomatique, $\mathrm{n}^{0}$ 21, Abril, 2010.

- Mobilizar os Territórios Produtivos: para além do capital social, a constituição do comum.in Territórios Produtivos. COCCO,G. e SILVA, G. (org.).Rio de Janeiro:DP\&A Editora, Brasília,DF: Sebrae,2006.

. MundoBraz - O devir-mundo do Brasil e o devirBrasil do mundo. Rio de Janeiro-São Paulo. Editora Record, 2009.

CORSINI, Leonora F. Êxodo Constituinte: multidão, democracia e migrações. Tese. Rio de Janeiro: Escola de Serviço Social/UFRJ:2007.

FERREIRA, Ademir Pacelli. O migrante na rede do outro. Rio de Janeiro: TeCorá Editora, 1999.

HALL, Stuart. Da diáspora. Identidades e Mediações Culturais. (org. Liv Sovik). Belo Horizonte: Editora UFMG, 2003.A precarização e a divisão internacional e sexual do trabalho. Sociologias, Porto Alegre, ano 11,n.21, jan/jun, 2009

LAZZARATO, Maurizio. Para uma definição do conceito de bio-política. Revista Lugar Comum. n. 5-6,1998.

LYOTARD, J A Condição Pós-Moderna.Rio de Janeiro: José Olympio, 2002.

MEZZADRA, Sandro. Direito de Fuga - migrações, cidadania e globalização. EdUnipop,PT, 2012. 
In Dossiê:

. Multiplicação das fronteiras e práticas de mobilidade.

"Migrações e Fronteiras"- revista REMHU - Brasília, ano XXIII, n.44, 2015 .

MOULIER-BOUTANG, Yann. Les chaînes de la migration en Europe. Multitudes, n.19, 31-40, dez. 2004

Antonio. Trabalho

. Introdução. In: LAZZARATO, Maurizio; NEGRI,

imaterial : formas de vida e produção de subjetividade. DP\&A editora: Rio de Janeiro, 2001.

NEGRI, Antonio; COCCO, Giuseppe. Glob(AL). Biopoder e luta em uma América Latina globalizada. Rio de Janeiro: Record, 2005.

NEGRI, Antonio, HARDT, Michael. O trabalho de Dionísio - Para a crítica ao Estado pós-moderno. Juiz de Fora/MG: Editora UFJF, 2004. . Império. Rio de Janeiro:Editora Record,2006. . Multidão - Guerra e democracia na era do Império. Rio de Janeiro/ São Paulo, 2005.

PERES,R,G. Os dois lados da fronteira: a imigração boliviana, gênero e o uso

estratégico dos espaços. Iforme Gepec, v.15, n.especial, Toledo, 2011.

OLIVEIRA, Antônio T, R. Migrações internacionais e políticas migratórias no Brasil. Cadernos OBMigra, v.1, n.3, 2015

SANSON, César. Trabalho e subjetividade: da sociedade industrial à sociedade pós- industrial tese de doutorado Universidade Federal do Paraná.-2009.

SAYAD, Abdelmalek. A imigração ou os paradoxos da alteridade. São Paulo: EDUSP, 1998.

migrante. Travessia, v.13, jan. 2000.

- O retorno: elemento constitutivo da condição do 


\section{Human Mobility in the Context of Change}

ABSTRACT: The article discusses the aspects and impacts of the changes of capitalism and the growing migratory flow in the 21st century. It analyzes the new configuration of capitalist power and the new productive ordering, where human mobility becomes a necessary condition.

KEYWords: Human Mobility. Work. Power.

Mariângela Moreira NASCIMENTO

Doutora em Ciência Política, docente do Departamento de Estudos de Gênero e Feminismos. Pesquisadora do grupo de pesquisa GIRA - Grupo de Estudos Feministas em Política e Educação. 